\title{
Realization of the artistic potential of the personality of students in the educational process: on the example of a pedagogical university
}

\author{
A.Y. Maksimenko ${ }^{1 *}, I . V$. Zargaryan $^{2}$, and E.O. Katranji ${ }^{3}$ \\ ${ }^{1}$ V.I. Vernadsky Crimean Federal University, Simferopol, Russia \\ ${ }^{2}$ V.I. Vernadsky Crimean Federal University, Simferopol, Russia \\ ${ }^{3}$ V.I. Vernadsky Crimean Federal University, Simferopol, Russia
}

\begin{abstract}
The article is devoted to the comprehension of modern problems of the development of the creative potential of the personality of students of a pedagogical university. The psychological and pedagogical nature of creative thinking is studied and emphasized, in accordance with which methods and conditions of teaching that need to be transformed are proposed. Taking into account the intensity of the influence of the informational space, the peculiarities of training and creative activity of students are also considered. A scientific method for the formation of creative ideas at the stage of search is proposed. The pedagogical conditions and requirements for teachers of the pedagogical department are formulated, which are necessary for the successful development of students' creative abilities. The proposals for stimulating the creative and cognitive activity of students are generalized, namely, for their inclusion in exhibition and project activities throughout the entire course of study. The features of the development of the artistic potential of a student's personality in artistic and educational activities are taken into account, the characteristics of the main level of development is given.
\end{abstract}

\section{A problem statement}

The urgency of the research topic is due to the fact that the XXI century is an era of opportunity creation. It makes high requests on the creative development of the individual. In society the social status of the creative profession is becoming higher and higher, aesthetic services are becoming more and more in demand, and the need for artists, architects, designers, restorers and other professions is growing. This encourages young people to choose actively this type of career at the stage of their professional selfdetermination [1].

If you look at the current state of education in Russia, you can see that it is characterized by qualitative changes in the field of content, the purpose of which is to develop students'

\footnotetext{
* Corresponding author: prof-ped.gpa@mail.ru
} 
creative thinking. The effectiveness of the Academy's work in the field of art education in this direction depends on the extent to which the educational process ensures the development of the creative abilities of each student, forms the student's creative personality, gets him ready for creative, cognitive and social and labor activities. In modern conditions, the main goal of a pedagogical university as a social institution is the multifunctional development of students, their cognitive interests, general cultural skills, self-education skills and, of course, creative abilities [2].

Now Russia needs people who are capable of making non-standard decisions and are able to think creatively. That is why fostering the creative abilities of students is the most important task of modern universities. In order to realize rich creative potential of students, it is necessary to create certain conditions, first of all, to involve students into truly creative activity. After all, as psychology has long believed, abilities are born and developed from preconditions.

The period of studying at the university is the most important period of the student's personal growth, the formation of his personality in professionally oriented activities. This is the time for the formation of cognitive and professional interests, positive spiritual work on oneself, self-awareness and the search for opportunities to realize one's potential. In the structure of the personal potential of creative students, a special place is occupied by artistic potential, which allows a person to realize the possibilities of the inner world and reveal a creative person. The formation of the creative personality is an important period for further realization of the individual potential. If we consider artistic potential as a special personal phenomenon, then we can say that it is characterized not only by development, but also by self-development associated with the cultural environment, professional education and the spiritual world of the individual [3].

In order to contribute to the development of the artistic potential of students in the conditions of studying at a university, it is necessary to take into account the psychological characteristics of adolescents. The youth (17-21) is the transition from adolescence (13-16) to maturity (22-55). Because of the high impulsiveness of adolescents and the necessary organizational maturity framework it is difficult for others to understand. Teenagers are psychologically more mobile and more inclined to hobbies, they need more intellectual discipline and attention. An adult, psychologically formed person, on the contrary, involuntarily is strongly attracted by something familiar, well-known, and his work manifests itself outside the framework of the organization, in spontaneous, unexpected actions and associations, even for himself.

Let's consider the basic concepts of this study. The question of human creativity as a phenomenon and its development is at the margin of psychology and pedagogy. This is due to the fact that the generic philosophy of the above-mentioned sciences determines the nature of human abilities in different ways. Two well-known theories are in opposition to each other: the first asserts that ability is a quality of the soul and is given to a person at birth in a ready-made form; the second - ability is a quality of personality training, that depends entirely on the living conditions and activities of a person. That is why the first theory is the scientific basis of psychology, repeatedly researched and proven, while the second refers to the field of pedagogy, influencing the formation of the concept of individual "condition of educational development" [4]. Since we are talking about creative abilities, which are the subject of the research, it is necessary to actualize the issue of its development.

The issue of the formation of the creative potential of an individual in a university environment is complex and combines several aspects: personality and creativity; general personality system as a whole; the creative potential of the personality in the process of its formation and development. Despite the natural ability for creative activity, only purposeful training and education can provide a high level of development of inborn creative abilities 
[5]. The formation of these abilities should take place at all stages of personality development.

The psychological aspects of the problem of the formation of creative potential are well studied, but the pedagogical foundations of this process are insufficiently described. In particular, the unresolved issue concerns the period of studying at the university. The modern pedagogical practice is trying to solve this problem in various ways: by introducing a student-centered approach to teaching, by making a leap through promising educational values, etc. There is a clear tendency for searching the means of developing thinking skills associated with the creative activity of students.

The main task facing the university today is the formation of a harmonious, socially active and creative student personality, possessing not only knowledge, but also the ability for self-development and self-education, capable of solving non-standard tasks that have no analogues in the past, of responding to changes in society in proper time, and, at the same time, of directing one's attention to eternal universal human values.

The analysis of the psychological and pedagogical literature on the study of this problem, as well as the experience of higher educational institutions, leads us to the conclusion that the problem of the formation of a student's creative potential in the educational process of a university has a number of contradictions: the contradiction between the needs of society in the formation of creative personality and insufficient attention to this problem in modern universities; the contradiction between the need to form the student's creative potential, the need for the actual implementation of this process in the educational activities of the university and the lack of its theoretical development and technical support [6].

The artistic potential of a person is transformed in the process of personal development and is not isolated from other personality traits, but interacts with them and is formed only within the framework of the creative process. To realize the artistic potential in artistic and educational activities, it is necessary to take into account the system of relationships reflected by the nature of its components (abilities, will, character, temperament, motivation, emotional enthusiasm and satisfaction in the process of activity). The important features of the development of artistic potential in the artistic and educational activities of students are emotional orientation, artistic and aesthetic experience, cognitive and creative interests, which determine the creative activity of the individual and ensure the student's interaction with the surrounding reality in the process of activity.

Currently, students entering pedagogical universities are characterized by different levels of artistic training and the development of artistic potential. In this regard it is necessary to determine the criteria for identifying the initial level of artistic capabilities (emotional expressiveness of the work of art, the integrity of the image, imaginative solutions), as well as the student's personal readiness for artistic activity (the creation of which can contribute significantly to the formation of the student's personality in the learning process) [5].

Based on this we have identified three levels of development of the personal artistic potential of students: low (cognitive-reproductive), medium (evaluative-creative) and high (artistic-transformative). In order to form and develop the artistic potential of a student's personality in the process of artistic and educational activities, it is recommended to use the model "Realization of the artistic potential of a student's personality in the process of university education". It consists of three stages ("I am a person", "I am an artist", "I am a creator"), each of them is a stage at which the student's personality rises from one subjective position to another ("I am a knower", "I am a transformer") [7].

The first stage ("I am a person") involves the students' acquiring of knowledge about themselves as a subject of creative cognition of objective reality. At this stage selfawareness of the personality is ensured, the student's understanding of one's personality, 
which is formed in the process of one's own creative activity. The artistic and educational activities of the respondents at this stage are carried out in the subjective position "I am omniscient". The student's understanding of oneself occurs in the context of the studied subject, through subjective experience. The second stage of the model ("I am an artist") is determined by the position of the respondent, who is aware of himself as a subject of artistic activity. At this stage students get acquainted with the artistic picture of the world (based on illustrations for works), master the artistic and aesthetic values of the surrounding reality in a visual and practical form of their own activities, and at this stage they acquire the artistic and cognitive activity of the individual, carrying out in the subjective position of "I". The third stage of the model ("I am a creator") involves the implementation of already acquired knowledge, skills and abilities in the situation where a person considers oneself to be a subject of creation. This stage is based on independent creative activity aimed at artistic transformation, improvement of the surrounding reality and the personality itself, both in a personal and professional way. Each stage in the development of artistic potential involves going beyond attitudes, acquaintance, learning, including going beyond one's own personality, thereby opening up new opportunities for self-awareness. After reaching a certain level of development, the student's personality starts to desire to change and master a new level, therefore, the development of artistic potential determines the desire of the personality to change constantly and master their abilities [8-13].

In the process of realizing the potential of the student's personality, its formation takes place. It is reflected in the aesthetic orientation of perception, in the improvement of moral and spiritual aspects manifested in the acquisition of the respondent (expanding of selfawareness, changing of attitudes towards oneself and the world, increasing of self-esteem, the ability of self-regulating of creative activity).

\subsection{The objective of the work}

The empirical measurement of the dynamics of creative qualities is possible by various methods. The most appropriate of them the authors consider to be questioning, testing, and expert assessment of teachers.

The students of the Federal State Autonomous Educational Institution of Higher Education "V.I. Vernadsky Crimean Federal University" took part in the study. The sample included 84 freshmen, 77 sophomores, 69 third-year students, and 58 fourth-year students. The sample size of the course varies because of students' sending down due to lack of funds for continuing their studies and due to other reasons. Students of humanitarian specialties are included in the sample. The sample loss on re-examination was $5.6 \%$.

\section{Results of the research}

According to the accepted concept, the creative potential includes opportunities for personal development offered by a set of selected qualities. Let's start with getting ready for the risk, and the survey results will be presented in Tables 1 and 2.

The analysis shows that the proportion of those for whom risk is the norm increases from the first to the last year of studying. The results are confirmed by the repeated question.

With those who take risks from time to time, the picture is reversed: their number grows, respectively, from 38 to $62 \%$. 
Table 1. The distribution of students' answers to the question "Do you risk getting bad marks by switching your attention to another type of activity, not academic, before exams, tests, test work?", \%.

\begin{tabular}{|l|l|l|l|}
\hline \multicolumn{3}{|c|}{ The Year of Studying } \\
\hline \multicolumn{1}{|c|}{ 1st-2nd } & 2nd-3d & \multicolumn{1}{c|}{ 3d-4th } & 4th-5th \\
\hline 4.3 & 4.5 & 13.7 & 12.9 \\
8.7 & 7.0 & 19.6 & 16.1 \\
\hline 47.8 & 58.2 & 37.3 & 29.0 \\
60.9 & 54.9 & 41.2 & 35.4 \\
\hline 43.5 & 35.8 & 29.4 & 38.7 \\
30.4 & 33.8 & 27.4 & 29.0 \\
\hline 8.7 & 7.5 & 19.6 & 19.4 \\
4.3 & 4.3 & 11.8 & 19.4 \\
\hline
\end{tabular}

Table 2. The distribution of students' answers to the question "Are your academic achievements the same in all the disciplines?", \%.

\begin{tabular}{|c|c|c|c|c|}
\hline \multirow{2}{*}{ The Variant of the Answer } & \multicolumn{4}{|c|}{ The Year of Studying } \\
\cline { 2 - 5 } & 1st-2nd & 2nd-3d & 3d-4th & 4th-5th \\
\hline The same & 4.3 & 4.4 & 4.1 & 9.7 \\
& 4.8 & 6.8 & 6.4 & 8.8 \\
\hline Almost the same & 39.1 & 57.4 & 58.8 & 45.2 \\
& 39.6 & 48.5 & 53.2 & 45.4 \\
\hline Very different & 8.7 & 8.8 & 25.4 & 30.2 \\
& 9.2 & 11.5 & 28.0 & 34.6 \\
\hline I can have excellent marks in some & 47.8 & 30.9 & 11.8 & 12.9 \\
disciplines, but fail others & 46.4 & 33.2 & 12.4 & 11.2 \\
\hline
\end{tabular}

Table 2 shows that, despite the difference between the directions in training, students have a lot in common in the distribution by options and dynamics. There is a fairly significant proportion of those who have almost the same marks, which, however, somewhat decreases towards the senior courses.

Among the students of the Federal State Autonomous Educational Institution of Higher Education "V.I. Vernadsky Crimean Federal University", with the deepening of professional specialization, there is a tendency for the growth of those who have very different assessments. In the fifth year of studying, it is already more than $30 \%$ of the surveyed students.

According to one of the hypotheses of the study, the unevenness of academic success may be caused by the conscious choice of fun and personality-developing activities, in part by impulsiveness as an element of temperament that is usually not suitable for development. Impulsiveness can be associated with unequal academic achievement.

In the Russian higher education system high assessment of academic progress is considered to be a sign of successful personal development. That is why the inclination to take risks, first of all, must be correlated with real academic success. The results of students' answers to this question are presented in Table 3.

Table 3. The results of testing the creative potential of students, scores.

\begin{tabular}{|l|l|l|l|}
\hline \multicolumn{3}{|c|}{ The Year of Studying } \\
\hline 1st-2nd & 2nd-3d & 3d-4th & 4th-5th \\
\hline 37 & 36 & 23 & 28 \\
\hline 32 & 35 & 26 & 27 \\
\hline
\end{tabular}


Based on the results of a comparative study of the creative potential of students' personality, the following conclusions can be drawn: a small sample survey of students of humanitarian specialties of different years of studying showed that the number of students according to the criteria of creative potential, analyzed during the survey, varied within 25 $35 \%$. No more than $10-12 \%$ of the students surveyed have all the necessary qualities.

In $50 \%$ of the surveyed students these qualities were weak or asymmetric. Every fifth student surveyed focused on the non-creative educational process at the university, from which it follows that there is not enough ground for the conclusion about the general development of the creative potential of the student's personality, as evidenced by the specific indicators of the creative personality in different years of studying. The authors believe that the reason is that, firstly, the foundation for this development is laid before entering higher educational institutions, and secondly, some students with creative potential are sent down for various reasons (the inability to finance education further, etc.). But, despite the influence of various circumstances, the proportion of students with creative potential remains quite stable.

\section{Conclusions}

Based on the results obtained, the following conclusions can be drawn:

1. Without teachers' understanding of the foundations of psychology, the psychological nature of creativity, without means and techniques that have a competent impact on the creative process of the student, it is impossible to realize the artistic potential of the personality of students in the educational process.

2. If the teacher does not understand his goal, namely: the formation of vivid creative thinking, positive cognitive activity of the student as the basis of the professional ability of the future artist-teacher, then the development of the student's creative potential is also impossible. That is, the task of a modern teacher of higher education is to educate a person who thinks, analyzes and is able to respond quickly and consciously to the processes of the surrounding world, with a high-quality level of professional skills.

3. In teaching visual arts, the importance of student-centered teaching methods is the key to a full assessment of the students' abilities and, therefore, the key to more effective learning and the development of the unique creative qualities of every person.

4. The creation of learning conditions adapted to the trends of the surrounding world is a factor that determines the success in solving the problem of developing students' creative abilities. We believe that the solution to the problem of developing creative potential lies in an interdisciplinary field, and the final quality component is the aesthetic education. We do not mean the summarizing of all the disciplines. However, when creating a thematic complex assignment aimed at studying technology and the implementation of educational tasks, teachers need not only to understand new trends in their subject matter, new technologies and materials that are actively included into the educational process, but also, consequently, to form the ability of students to choose information independently, which will contribute to the development of creative thinking.

It is also necessary to organize excursions to exhibitions. After that, it will be useful to conduct a conversation in the audience, to analyze what has been seen, to study and compare the creative experience of different authors. It is this approach that will solve the problem of developing students' creative abilities here and now, in accordance with the trends and conditions of our time.

The theoretical model of the functioning of the educational process and the formation of the creative potential of the student at the university is based on creative educational and cognitive activity. The effectiveness of the formation of the creative potential of students in 
educational and professional activities depends on the maximum disclosure of age and personal characteristics and abilities of every student.

\section{References}

1. A.V. Khutorskoy, Key Competencies as a Component of Student-Centered Education, Public Education, 2, 58-64 (2017)

2. V.I. Andreev, The Center for Innovative Technologies, 500 (2018)

3. I.V. Davydova, Development of the Creative Potential of Students of a Pedagogical University in the Process of their Joint Educational Activities, 24 (2019)

4. S.I. Pozdeeva, A.V. Obskov, Diagnostics of the Functional and Semantic Content of Joint Activities and the Position of a Teacher at a Foreign Language Lesson at a Technical University, TSPU Bulletin, 1 (178), 119-125 (2017)

5. S.P. Akutina, Developing Potential of Creative Workshops in Modern Psychological and Pedagogical Education, Young Scientist, 12 (2017)

6. R.B. Dondokova, Development of the Teacher's Creative Potential in the Context of the Humanization of Education, Bulletin of BSU, 4, 35-38 (2017)

7. S.S. Savelyeva, Pedagogical Conditions for the Formation of Teacher's Professional Competence in the Educational Process of the University, 220 (2018)

8. E.V. Senichkina, Creative and Cognitive Activity of Students of the Art and Graphic Department, Internet Magazine "Pedagogy of Art", 2, 91-95 (2017)

9. O.Yu. Malakhova, Role of the Reflective Educational Environment in the Professional and Personal Self-Determination of a University Student, Education and Society, 1 (90), 87-91 (2016)

10. L.D. Medvedeva, On the Training of Economic Specialists in the Context of Globalization, TSPU Bulletin, 2 (80), 76-79 (2019)

11. T.V. Myasnikova, Motivation for Teaching Students through Modeling, Young Scientist, 18 (77), 614-617 (2017)

12. S.I. Pozdeeva, A.V. Obskov, Diagnostics of the Functional and Semantic Content of Joint Activities and the Position of a Teacher at a Foreign Language Lesson at a Technical University, TSPU Bulletin, 1 (178), 119-125 (2017)

13. E. Winner, The origins and Ends of Giftedness, American Psychologist, 52, 159-169 (2019) 